E. Lazoura

M.J. McLeish

M.-I. Aguilar

\section{Studies on the conformational properties of $\mathrm{CP}-10^{42-55}$, the hinge region of $\mathrm{CP}-10$, using circular dichroism and RP-HPLC}

Key words: $\alpha$-helix; binding affinity; RP-HPLC; hydrophobic contact area; CP-10

E. Lazoura and M.-I. Aguilar, Department of Biochemistry and Molecular Biology, Monash University, Clayton, Victoria, Australia.

M.J. McLeish, Department of Medicinal Chemistry, Victorian College of Pharmacy, Monash University, Parkville, Victoria, Australia; present address: College of Pharmacy, University of Michigan, 428 Church Street, Ann Arbor, MI 48109-1065, USA.

\section{Correspondence to:}

M.-I. Aguilar

Department of Biochemistry and Molecular Biology

PO Box 130

Monash University

Victoria 3800

Australia

Tel: +61-3-9905-3723

Fax: $+61-3-9905-5882$

E-mail: mibel.aguilar@med.monash.edu.au

Dates:

Received 16 July 1999

Revised 3 September 1999

Accepted 27 October 1999

To cite this article:

Lazoura, E., McLeish, M.J. @) Aguilar, M.-I. Studies on the conformational properties of CP-1 $\mathrm{O}^{42-55}$, the hinge region of CP-10, using circular dichroism and RP-HPLC.

I. Peptide Res., 2000, 55, 411-418.

Copyright Munksgaard International Publishers Ltd, 2000 ISSN $1397-002 \mathrm{X}$
Abstract: The conformational properties of CP-10 $12-55$, a peptide corresponding to the hinge region of $\mathrm{CP}-10$, were investigated using circular dichroism spectroscopy and reverse-phase highperformance liquid chromatography (RP-HPLC). The circular dichroism studies indicated that $\mathrm{CP}-10^{42-55}$ formed considerable secondary structure in the presence of hydrophobic solution environments including $50 \%$ acetonitrile, $50 \%$ trifluoroethanol and $200 \mathrm{~mm}$ sodium dodecyl sulfate, which comprised a mixture of $\alpha$-helix and $\beta$-sheet. The effect of temperature on the conformation of $\mathrm{CP}-10^{42-55}$ was investigated between 5 and $40^{\circ} \mathrm{C}$, with very small changes in the spectra being observed. RP-HPLC was then used to investigate the effect of temperature on the conformation of $\mathrm{CP}-10^{42-55}$ in the presence of a hydrophobic surface. Using a $\mathrm{C}_{18}$-adsorbent, CP-10 $0^{42-55}$ exhibited a conformational transition at $25^{\circ} \mathrm{C}$, which was associated with an increase in the chromatographic contact area and the binding affinity of the peptide for the stationary phase. In addition, near-planar bandbroadening behaviour indicated that conformational species interconverted with rapid rate constants compared with the chromatographic time scale. These results indicated that the conformational change at $25^{\circ} \mathrm{C}$ in the RP-HPLC system most likely corresponds to the unfolding of an $\alpha$-helical and/or $\beta$-sheet structure to an extended coil structure. Therefore, the strong chemotactic properties of this peptide may be attributed to its ability to form considerable secondary structure in the presence of a hydrophobic environment.

Abbreviations: Boc, tert-butyloxycarbonyl; $C D$, circular dichroism; LPL, low-density lipoprotein; LSS, linear solvent strength; MeCN, acetonitrile; $\mathrm{PHE}_{5}$, penta-L-phenylalanine; RP-HPLC, reverse-phase high-performance liquid chromatography; SDS, sodium dodecyl sulfate; TFA, trifluoroacetic acid; TFE, trifluoroethanol. 
CP-10 (chemotactic protein; molecular mass $10.3 \mathrm{kDa}$ ) is a murine chemotactic cytokine with potent chemotactic activity for phagocytic or myeloid cells both in vivo $(1,2)$ and in vitro $(2,3)$. CP-10 is a calcium-binding protein and a member of the S1oo superfamily (4). While the function of most $S_{100}$ proteins is unknown, they are generally believed to be involved in cell regulatory processes and are associated with cell differentiation (4). Recently, Devery et al. (3) demonstrated that CP-10 has a fundamental extracellular function as a potent chemotactic agent, which is involved in phagocyte recruitment during inflammatory reactions. Furthermore, the 'hinge' region, corresponding to residues $42-55\left(\mathrm{CP}-1 \mathrm{O}^{42-55}\right)$, also elicited a positive inflammatory reaction when injected into rat skin and had chemotactic activity for thioglycollate-elicited murine cells in vitro (2). Intraperitoneal injection of $\mathrm{CP}-10^{42-55}$ into mice caused sustained leukocyte recruitment with a 6 -fold increase in monocyte numbers over $24 \mathrm{~h}$. In addition, CP-10 $\mathrm{O}^{42-55}$ elicited monocyte/macrophage accumulation significantly increased the level of cholesteryl esters in response to acetylated low-density lipoprotein (LDL), both in vivo and in vitro and this was associated with a 2 -fold increase in scavenger receptor expression (5). The initial events of monocyte recruitment and adhesion to vessel walls may be important in macrophage foam cell development and CP-10 may, therefore, contribute to early inflammatory events of atherogenesis by stimulating these events. In particular, $\mathrm{CP}-1 \mathrm{O}^{42-55}$ may constitute the region of $\mathrm{CP}-10$ that is responsible for the chemotactic activity of the protein (2).

The aim of this study was to investigate the solution and interactive properties of the $\mathrm{CP}-1 \mathrm{O}^{42-55}$ peptide in order to provide insight into the conformational properties of this region of $\mathrm{CP}-10$. The solution studies were designed to provide insight into the conformation adopted by the peptide in various hydrophobic environments. Furthermore, considering $\mathrm{CP}-1 \mathrm{O}^{42-55}$ exhibits strong chemotactic activity for myeloid cells $(1-3)$, investigations into the interactive behaviour of CP-10 $0^{42-55}$ with a hydrophobic surface $\left(\mathrm{C}_{18^{-}}\right.$ ligands) were carried out to provide insight into the conformational integrity of this region of CP-10 upon interaction with a hydrophobic lipid-like surface.

\section{Experimental Procedures}

\section{Peptide synthesis}

CP-10 $10^{42-55}$ (H-PQFVQNINIENLFR-OH; $\quad M_{\mathrm{r}}=1731.8$ ), synthesized as described by Lackmann et al. (2), was generously provided by Dr Paul Alewood (Centre for Drug Design and Development, University of Queensland, Brisbane, Australia). Additional quantities of the peptide were synthesized using standard tert-butyloxycarbonyl (Boc) solid-phase procedures (6).

\section{Circular dichroism studies}

2,2,2-Trifluoroethanol (TFE) and sodium dodecyl sulfate (SDS) were obtained from Aldrich (Milwaukee, WI, USA), while acetonitrile (HPLC grade; MeCN) was obtained from Mallinckrodt (Paris, KY, USA). Water was quartz-distilled and deionized in a Milli-Q system (Millipore, Bedford, MA, USA).

Circular dichroism (CD) spectra were measured over the range 190-240 nm, using a Jasco-710 spectropolarimeter (Tokyo, Japan) coupled to a Neslab RTE111 circulating water bath (Portsmouth, NH, USA). The instrument was calibrated using $d$-10-camphorsulfonic acid. Spectra were obtained at 5, 25 and $40^{\circ} \mathrm{C}$ using cells with a path length of $0.1 \mathrm{~cm}$. Solutes were dissolved in $\mathrm{H}_{2} \mathrm{O}, 50 \% \mathrm{MeCN}, 50 \%$ TFE and $200 \mathrm{~mm}$ SDS solutions. Peptide concentrations of 100 and $200 \mu \mathrm{M}$ were used and were determined by quantitative amino acid analysis. Data points were recorded at a scan speed of $20 \mathrm{~nm} / \mathrm{min}$, bandwidth of $1.0 \mathrm{~nm}, 1 \mathrm{~s}$ response and $0.1 \mathrm{~nm}$ resolution. Five repeat scans were used to obtain the final averaged spectra. Following baseline correction, the observed ellipticity, $\theta$, was converted to mean residue ellipticity $[\theta]\left(\mathrm{deg}_{\mathrm{cm}} / \mathrm{dmol}\right)$, using the relationship $[\theta]=\theta /(1 c N)$ where 1 is the path length in millimeters, $c$ is the molar concentration and $N$ is the number of residues in the peptide. If required, spectra were smoothed using the Jasco Fast Fourier Transform algorithm. The percentage of $\alpha$-helix was determined using the method of Chen et al. (7) with the ellipticity at $222 \mathrm{~nm}$, and the results are listed in Table 1.

\section{Reverse-phase high-performance liquid chromatography studies}

\section{Chromatographic procedures}

All chromatographic measurements were performed on a Hewlett Packard (Walbronn, West Germany) HP1090M high-performance liquid chromatography (HPLC) system equipped with a $\mathrm{DR}_{5}$ solvent delivery system, an automated injection and sampling system, and an HP109o diode-array detector (monitoring wavelength, $214 \mathrm{~nm}$ ). Column temperatures $\left(5-85^{\circ} \mathrm{C}\right)$ were controlled by immersing the column in a thermostated column water jacket coupled to a recirculating cooler (Cole Palmer, Illinois, USA). Chro- 
Table 1. Secondary structure

analysis of $\mathrm{CP}-10^{42-55}$ in

various solution environments

\begin{tabular}{lcl}
\hline Environment & $\begin{array}{l}\text { Temp. } \\
\left({ }^{\circ} \mathrm{C}\right)\end{array}$ & $\% \alpha$-helix $^{\mathrm{a}}$ \\
\hline $50 \% \mathrm{MeCN}$ & 5 & 19 \\
$50 \% \mathrm{MeCN}$ & 25 & 23 \\
$50 \% \mathrm{MeCN}$ & 40 & 21 \\
$50 \% \mathrm{TFE}$ & 5 & 51 \\
$50 \% \mathrm{TFE}$ & 40 & 51 \\
$200 \mathrm{~mm}$ SDS & 5 & 20 \\
$200 \mathrm{~mm}$ SDS & 40 & 20 \\
\end{tabular}

a. $\alpha$-Helicity determined according to (7).

matographic analysis and peak integration were performed by the IBM compatible HP Chemstation software.

Chromatography was performed with a Bakerbond Analytical Wide-pore $n$-octadecyl $\left(\mathrm{C}_{18}\right)$ silica reversed phase column (J.T. Baker, Phillipsburg, NJ, USA) with dimensions of $250 \times 4.6 \mathrm{~mm}$ internal diameter and containing adsorbent of $5 \mu \mathrm{m}$ nominal particle diameter and $30 \mathrm{~nm}$ average pore size. Bulk solvents were filtered under vacuum and degassed by sparging with helium. Linear gradient elution was performed using $0.1 \%$ trifluoroacetic acid (TFA) in water (buffer A) and 0.09\% TFA in acetonitrile/water (50:50; buffer B) over gradient times of 30,60,90, 120, 150 and $180 \mathrm{~min}$ with a flow rate of $1 \mathrm{~mL} / \mathrm{min}$ at temperatures of $5,15,25,35$, $45,55,65,75$ and $85^{\circ} \mathrm{C}$. The control solute, penta-Lphenylalanine $\left(\mathrm{PHE}_{5}\right)$, was obtained from Sigma (St. Louis, MO, USA). Peptide solutions were prepared by dissolving the solute at concentrations of $1 \mathrm{mg} / \mathrm{mL}$ in $0.1 \%$ TFA in water and stored until use at $-20^{\circ} \mathrm{C}$. A $25-\mu \mathrm{L}$ injection of the various $0.2 \mathrm{mg} / \mathrm{mL}$ solutions was used for all chromatographic experiments. All data points were derived from duplicate measurements with retention times between replicates varying by $<_{1} \%$. The column dead time, $t_{\mathrm{o}}$ was taken as the retention volume of the noninteractive solute, sodium nitrate, and the gradient elapse time was determined from the difference between the onset of mobile phase breakthrough, as monitored by the HP1090 diodearray detector, and the column dead time.

All chromatographic parameters, $\log \bar{k}, \bar{\psi}, S$-value and $\log$ $k_{\mathrm{o}}$ were calculated as described previously (8) using a template spreadsheet created in Excel 5.0 (Microsoft ${ }^{\mathbb{R}}$ 1983-95 Microsoft Corporation) that allowed for the rapid statistical analysis of data and simultaneous graphic representation of results. The input values required for calculations included: initial/final organic solvent concen- trations as a percentage, the column void $\left(t_{\mathrm{o}}\right)$ and elapse $\left(t_{\mathrm{e}}\right)$ time, the gradient times and corresponding retention times, and the bandwidth for each gradient time and temperature.

In addition, the following parameters were included to identify each experiment: peptide/column/HPLC details, buffer $\mathrm{A}$ and $\mathrm{B}$ composition and flow rate.

The bandwidths were measured at $13.4 \%$ of the eluted peak height, which corresponds to four standard deviations $(4 \sigma)$. Bandwidths between replicates typically varied by $<5 \%$.

\section{Results and Discussion}

\section{Studies}

In order to investigate the conformational preferences of $\mathrm{CP}$ $10^{42-55}$ in a range of hydrophobic environments, CD spectra were obtained for $\mathrm{CP}-1 \mathrm{O}^{42-55}$ in $50 \% \mathrm{MeCN}, 50 \% \mathrm{TFE}$ and $200 \mathrm{~mm}$ SDS and are shown in Fig. 1. Unfortunately, spectra in aqueous buffer could not be obtained because of the poor solubility of the peptide in water. In general terms, the spectra showed broad mimima between 205 and $220 \mathrm{~nm}$, indicating that the peptides adopted a considerable degree of secondary structure. However, the broad minima were indicative of a mix of conformers, as neither the double minima at 208 and $222 \mathrm{~nm}$ (typical $\alpha$-helix) nor the single minimum at $215 \mathrm{~nm}$ ( $\beta$-sheet) were observed.

The helical content of the peptide in each of the three environments was calculated using the ellipticity at $222 \mathrm{~nm}$ according to the method of Chen et al. (7), with the results listed in Table 1. Similar values were obtained for the $\alpha$ helical content of CP-10 $\mathrm{O}^{42-55}$ in $50 \% \mathrm{MeCN}$ and $200 \mathrm{~mm}$ SDS, while the $\alpha$-helical content of CP-10 $0^{42-55}$ in 50\% TFE was considerably higher. Because of the hydrophobic nature

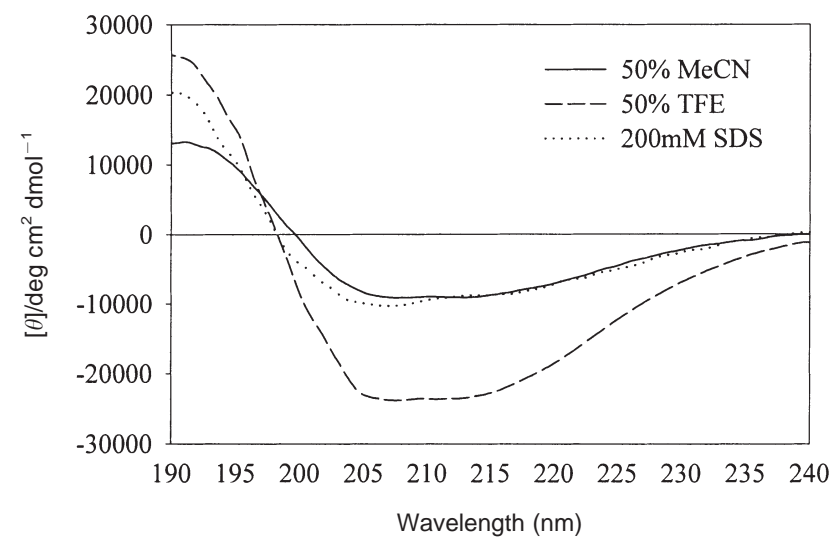

Figure 1. CD spectra of CP-10 $0^{42-55}$ in $50 \% \mathrm{MeCN}, 50 \% \mathrm{TFE}$ and $200 \mathrm{~mm}$ SDS at $5^{\circ} \mathrm{C}$ at peptide concentrations of $100 \mu \mathrm{M}$. 
of the peptide, this increase in $\alpha$-helical content may be due, at least in part, to a greater solubility of the peptide at higher TFE concentrations. No change in the spectrum was observed when the peptide concentration was doubled from 100 to $200 \mathrm{~mm}$ in $50 \%$ TFE. In order to investigate the relative stability of the peptide in different hydrophobic environments, CD spectra were obtained at temperatures ranging between 5 and $40^{\circ} \mathrm{C}$. The stability of the peptide in $50 \%$ TFE is evident in Fig. $2 \mathrm{~B}$, where little change in the spectrum was observed as the temperature increased to $40^{\circ} \mathrm{C}$. Similarly, in both $50 \% \mathrm{MeCN}$ (Fig $2 \mathrm{~A}$ ) and $200 \mathrm{~mm}$ SDS (Fig. 2C), the peptide exhibited no significant changes in spectra as the temperature was increased. Overall, the results indicate that the degree of secondary structure remained unchanged up to $40^{\circ} \mathrm{C}$.

\section{RP-HPLC Studies}

\section{Theoretical considerations}

The CD studies indicated that CP-10 $\mathrm{O}^{42-55}$ formed a mixture of $\beta$-sheet and $\alpha$-helical structure in a hydrophobic solution environment. Subsequently, the interactive properties of CP-10 $0^{42-55}$ with the $\mathrm{C}_{18}$-ligands in the RP-HPLC system were investigated in order to gain insight into the conformational properties of this peptide in the presence of a hydrophobic lipid-like surface that mimics the cell surface.

The negligible contribution of electrostatic and $\mathrm{H}$-bonding effects in RP-HPLC provides a means of studying the induction and stabilization of peptide secondary structure in the presence of a hydrophobic surface. Considering that the retention of a peptide solute is influenced by its hydrophobicity, the chromatographic contact area, the dielectric constant of the solvent and the bulk surface tension $(10,11)$, RP-HPLC provides a powerful technique to analyse the surface-induced hydrophobic stabilization of peptides corresponding to structured regions within a protein $(8,12-14)$, and to investigate the lipid-binding properties of peptides involved in membrane interactions $(15,16)$.

The linear solvent strength (LSS) model has been used to evaluate the interactive behaviour of peptides/proteins during the elution process and provides useful information, under linear gradient elution conditions, regarding the physicochemical properties of a solute $(8,12,13,17,18)$. Given the solute retention times $\left(t_{\mathrm{g}} 1\right.$ and $\left.t_{\mathrm{g}}\right) \mid$ for the corresponding gradient times $\left(t_{G^{1}}\right.$ and $\left.t_{G^{2}}\right)$, the chromatographic contact area ( $S$-value) and the binding affinity (log $k_{\mathrm{o}}$ ) can be derived from linear regression analysis according to:
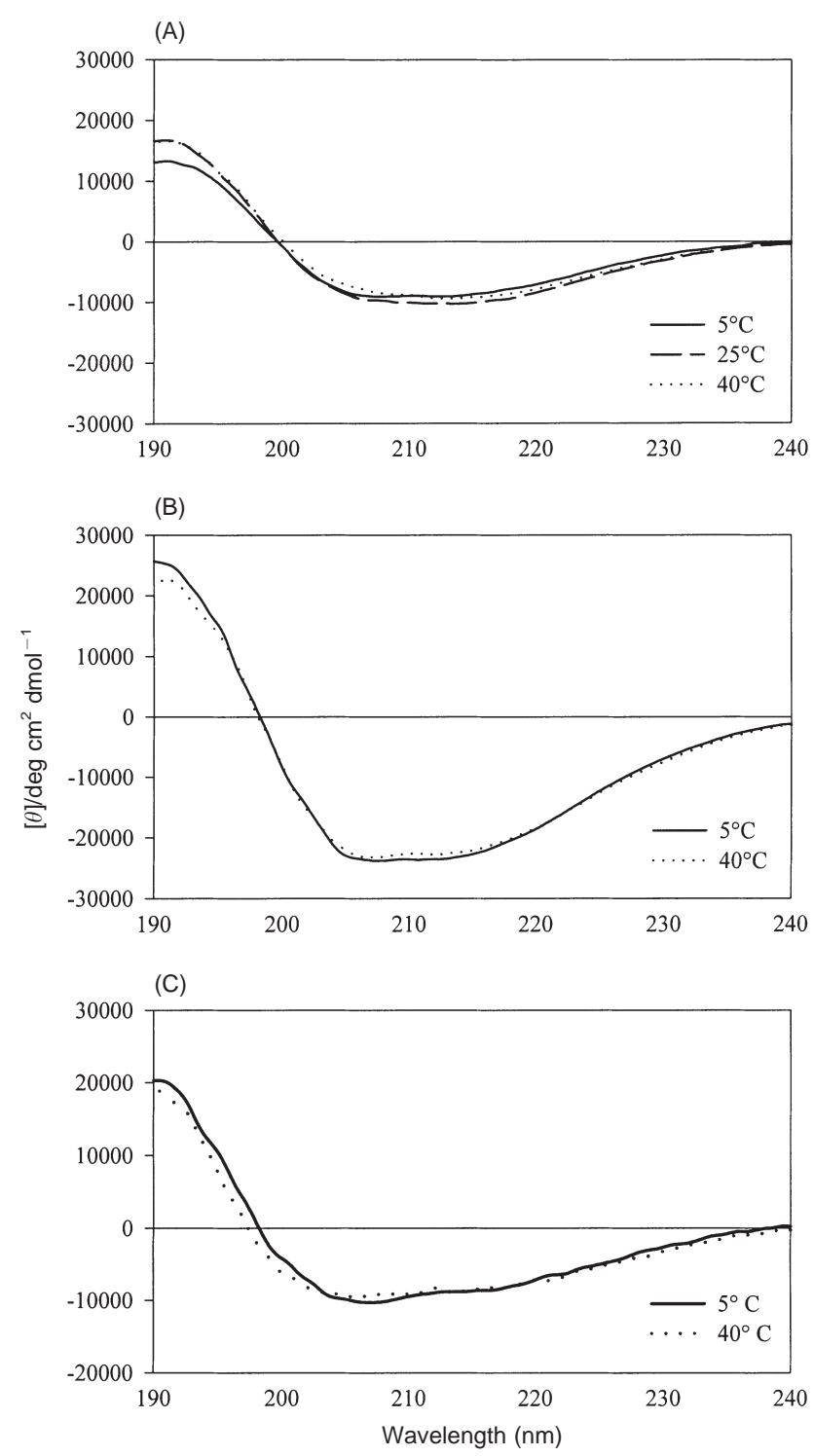

Figure 2. (A) CD spectra of $\mathrm{CP}-10^{42-55}$ in $50 \% \mathrm{MeCN}$ at $5^{\circ} \mathrm{C}, 25^{\circ} \mathrm{C}$ and $40^{\circ} \mathrm{C}$. (B) CD spectra of CP-10 $0^{42-55}$ in $50 \%$ TFE at $5^{\circ} \mathrm{C}$ and $40^{\circ} \mathrm{C}$. (C) CD spectra of CP- $10^{42-55}$ in 200 SDS at $5^{\circ} \mathrm{C}$ and $40^{\circ} \mathrm{C}$ at peptide concentrations of $100 \mu \mathrm{M}$

$\log \bar{k}=\log k_{\mathrm{o}}-\mathrm{S} \bar{\psi}$

where $\log \bar{k}$ is the logarithmic median capacity factor and $\bar{\psi}$ is the corresponding median organic mole fraction. The $S$ value can be derived from the slope of a plot of $\log \bar{k}$ vs. $\bar{\psi}$ and $\log k_{\mathrm{o}}$ is the intercept on the $\log \bar{k}$ axis at $\bar{\psi}=\mathrm{o}$.

In RP-HPLC, $\log k_{\mathrm{o}}$ values provide useful information regarding the relative affinity of the solute surface for the chromatographic ligands, while the $S$-value can be related to the hydrophobic contact area as derived from the solvophobic theory $(10,19,20)$ according to:

$\log k^{\prime}=\log k o-\gamma \cdot N \Delta A h+4.836 N^{1 / 3}\left(\kappa^{e}-1\right) V^{2 / 3} / 2.303 R T$ 
where $\Delta A_{\mathrm{h}}$ is the relative hydrophobic contact area, $\gamma$ is the mobile phase surface tension, which is directly related to the organic mole fraction, $\mathrm{N}$ is Avogadro's number, $V$ is the mean molar volume of the solvent, $\mathrm{R}$ is the gas constant and $\mathrm{T}$ is the absolute temperature. $k^{\mathrm{e}}$ is the ratio of the energy required for the formation of a cavity with the surface area equal to the solute surface area and the energy required to extend the planar surface of the liquid by the same area.

The relationship between the $S$-value in the LSS theory and $\Delta A_{\mathrm{h}}$ in the solvophobic theory (20) can be derived by combining equations 1 and 2 to give:

$S=N \Delta A h+4.836 N^{1 / 3}\left(\kappa^{e}-1\right) V^{2 / 3} / 2.303 R T=a \Delta A h+b \kappa^{e}-c(3)$

where $a, b$ and $c$ are constants.

Therefore, the $S$-value can be related to the relative hydrophobic contact area $\left(\Delta A_{h}\right)$ and the solvent cavity term $\left(\kappa^{\mathrm{e}}\right)$. While $\kappa^{\mathrm{e}}$ is related to the molar volumes of the solute and the solvent molecules, it approaches unity as the size of the peptide solute increases with respect to the solvent molecule. Therefore, unfolding of the peptide solute results in relatively small changes in $\kappa^{\mathrm{e}}$, which in turn will not contribute significantly to changes in $S$-value. Considering that peptides interact with RP-HPLC sorbents in an orientation specific manner, the role of the hydrophobicity of the peptide is vital. However, the localized areas of hydrophobicity define the hydrophobic binding domain, which controls the orientation and binding of a peptide to a hydrophobic surface. Accordingly, the main contribution to changes in $S$-value arises from changes in the hydrophobic binding domain associated with the unfolding of a peptide. The $\log k_{\mathrm{o}}$ value is related to changes in free energy associated with the adsorption of the solute to the nonpolar stationary phase, in the absence of organic modifier (20). The $\log k_{\mathrm{o}}$ can therefore be related to the affinity of the solute for the stationary phase at $\bar{\psi}=\mathrm{o}$ (initial conditions).

The interactive surface of a peptide or protein in the RPHPLC system consists of both sequentially and nonsequentially linked amino acids because of the presence of solute secondary structure. Analysis of the $S$-value and $\log k_{\mathrm{o}}$ can thus be used to gain insight into the hydrophobic contact area and binding affinity of the peptide solute for the stationary phase, respectively. The use of temperature to perturb the structure of the solute subsequently allows a detailed thermodynamic analysis of the conformational behaviour of the solute during interaction with the adsorbent. In contrast to small molecules, which do not exhibit conformational changes over the range of temperatures studied (20), peptides and proteins exhibit significant changes in the retention parameters, $S$-value and $\log k_{\mathrm{o}}$
$(8,12,13,21)$. Therefore, changes in $S$-value and $\log k_{\circ}$ as a function of temperature represent a powerful probe of conformational integrity. In the present study, the temperature-induced changes in hydrophobic contact area and binding affinity of $\mathrm{CP}-1 \mathrm{O}^{42-55}$ by the hydrophobic ligands was investigated.

\section{Dependence of retention on temperature}

The retention behaviour of $\mathrm{CP}-1 \mathrm{O}^{42-55}$ was investigated using a $\mathrm{C}_{18}$-adsorbent and $50 \%$ acetonitrile as the organic modifier and compared with that of the control solute, $\mathrm{PHE}_{5}$. The $S$-values and $\log k_{\mathrm{o}}$ were determined at 5, 15, 25, $35,45,55,65,75$ and $85^{\circ} \mathrm{C}$, from regression analysis of the $\log \bar{k}$ vs. $\bar{\psi}$ plots according to equation 1 . The dependence of the $S$-values and $\log k_{\mathrm{o}}$ on temperature, are shown in Fig. 3. These results demonstrate that at $25^{\circ} \mathrm{C}, \mathrm{CP}-10^{42-55}$ exhibited an increase in the chromatographic contact area with a concomitant increase in binding affinity for the $\mathrm{C}_{18}$-ligands. This result contrasts with the linear dependence of the $S$-values and $\log k_{\mathrm{o}}$ on temperature, also shown in Fig. 3, for the small molecular mass control solute, $\mathrm{PHE}_{5}$, which does not adopt any significant degree of secondary structure. The large change in $S$-values and $\log k_{\mathrm{o}}$ seen for CP-10 $\mathrm{O}^{42-55}$ therefore indicates that it undergoes a change in secondary structure at $25^{\circ} \mathrm{C}$. The effect of the conformational changes on the binding behaviour can also be seen in the elution profiles for $\mathrm{PHE}_{5}$ and $\mathrm{CP}-1 \mathrm{O}^{42-55}$, shown in Fig. $4 \mathrm{~A}, \mathrm{~B}$, respectively. For $\mathrm{PHE}_{5}$, a steady decrease in retention time was seen with increases in temperature, which is reflected in the constant $S$-values and $\log k_{\mathrm{o}}$ in Fig. 3 . In contrast, there was a significant discontinuity in the retention times for $\mathrm{CP}-10^{42-55}$ at 25 and $45^{\circ} \mathrm{C}$, which translates into the changes in $S$-values and $\log k_{\mathrm{o}}$ observed at these temperatures.

The CD studies discussed above indicated that this peptide is relatively stable in hydrophobic solution environments. However, the RP-HPLC system indicated that a conformational transition occurred at $25^{\circ} \mathrm{C}$, such that the peptide had a larger binding domain with a higher binding affinity. At temperatures $>25^{\circ} \mathrm{C}$, the hydrophobic binding domain and affinity returned to values similar to those at 5 and $15^{\circ} \mathrm{C}$, suggesting that $\mathrm{CP}-10^{42-55}$ unfolded further to a conformation with a chromatographic contact area and binding affinity that was similar to that observed below the transition. The CD studies in micellar SDS, acetonitrile and TFE indicated that CP-10 $0^{42-55}$ can adopt a partially helical conformation in the presence of a hydrophobic environment. While more spectroscopic evidence for the structural interconversion is required, it is not unreasonable to suggest 


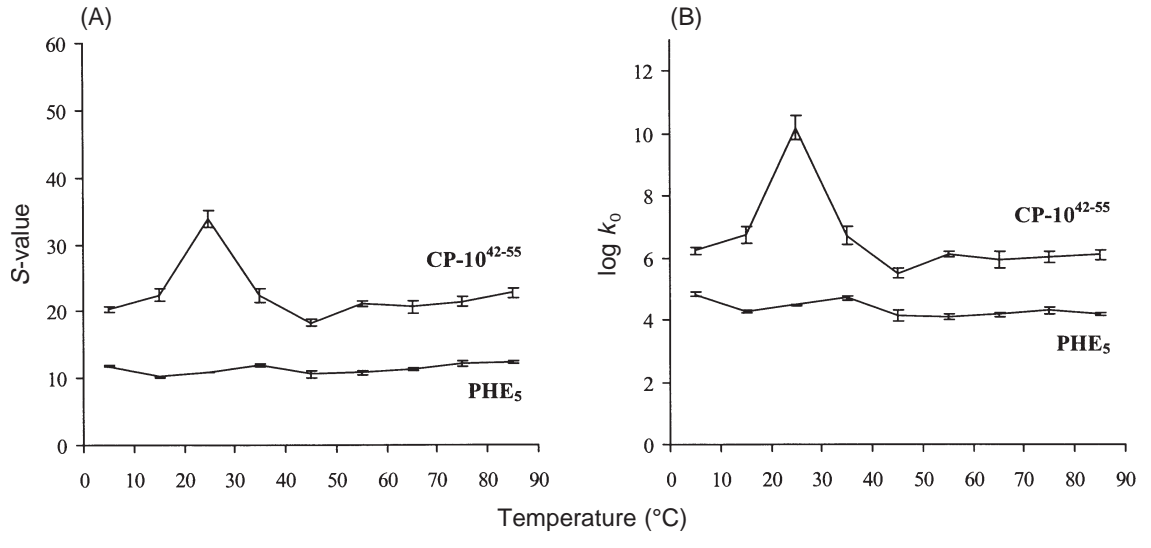

Figure 3. Dependence of (A) S-values and (B) $\log k_{\mathrm{o}}$ on temperature for $\mathrm{CP}-1 \mathrm{O}^{42-55}$ and $\mathrm{PHE}_{5}$ chromatographed on a $\mathrm{C}_{18}$-stationary phase using acetonitrile as the organic modifier. that the retention changes at $25^{\circ} \mathrm{C}$ in the RP-HPLC studies may correspond to the unfolding of peptide secondary structure.

\section{Dependence of bandwidth on temperature and gradient time}

The interactive behaviour of the $\mathrm{CP}-10^{42-55}$ peptide during the chromatographic process can be further characterized in terms of the binding dynamics through analysis of the experimental bandwidth. In gradient elution, bandbroadening exhibited by small, low molecular mass molecules with a rigid conformation, arises from: (i) axial dispersion in the bulk mobile phase, (ii) dispersion due to low mass transfer across the solvent-particle boundary and in the intraparticulate spaces, and (iii) from dispersion due to slow mass transfer of the solute at the stationary phase

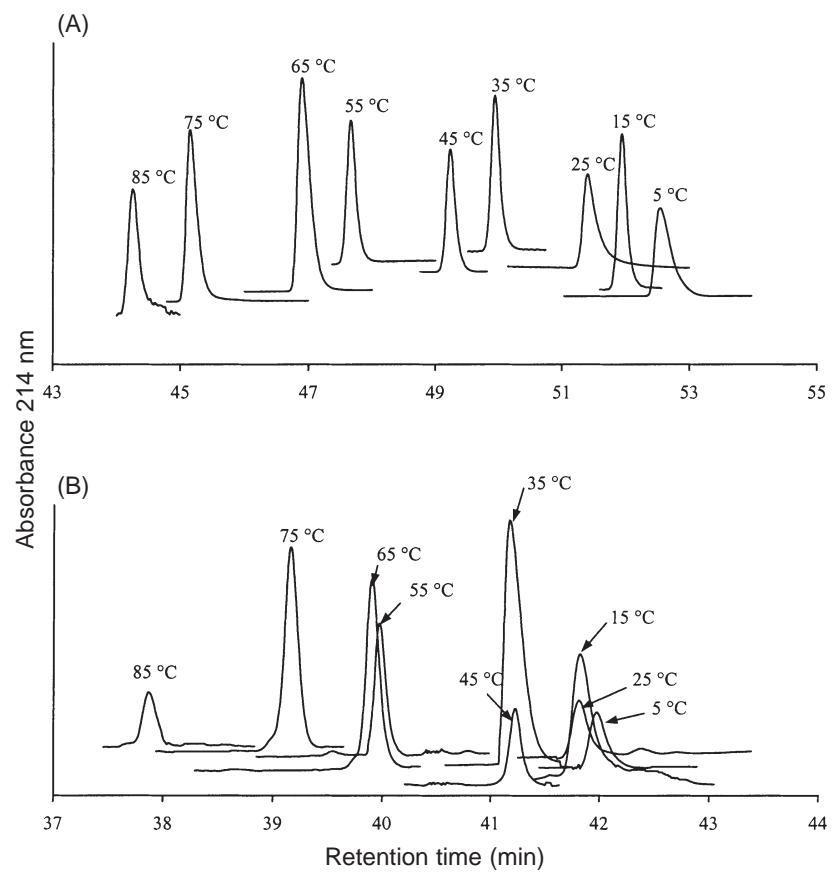

Figure 4. Chromatographic profiles of (A) $\mathrm{PHE}_{5}$ and (B) $\mathrm{CP}-1 \mathrm{O}^{42-55}$ at $5,15,25,35,45,55,65,75$ and $85^{\circ} \mathrm{C}$ using a 60 -min gradient time and monitored at $214 \mathrm{~nm}$. surface (16). Based on the assumptions that the surface area, hydrodynamic volume and the respective diffusivity of a single solute molecule remain constant throughout the chromatographic process, a Gaussian peak will be observed for small organic compounds with a rigid conformation $(8,13,22)$. In contrast, when peptides undergo conformational transitions during the separation process, the changes in structure result in changes in the interactive contact area, which in turn alter the retention time of the peptide. The shape of the experimentally observed peak depends, therefore, on the nature of the structural intermediates formed during the unfolding process, and the rate of interconversion between the fully folded and fully unfolded states. If the rate of conversion is faster or slower than the chromatographic time scale, no band-broadening behaviour is observed, and a single narrow peak is eluted corresponding to either the fully unfolded or fully folded conformer. However, if the rate of interconversion is similar to the chromatographic separation time, structural intermediates that have different retention times may be trapped at the surface giving rise to broad asymmetric or split peaks, as observed previously for a range of $\alpha$-helical, $\beta$-sheet and $\beta$-turn containing peptides $(8,13)$.

The dependence of bandwidth on temperature and gradient time for CP-10 $\mathrm{O}^{42-55}$ exhibited near-planar bandbroadening behaviour (8), which was similar to that observed for $\mathrm{PHE}_{5}$ (data not shown). This result indicates that the interconversion between conformational species, which was evident from the retention data at $25^{\circ} \mathrm{C}$, occurred at a faster rate than the chromatographic separation time. The similarity in the bandwidth behaviour of $\mathrm{PHE}_{5}$ and CP$10^{42-55}$ is also evident from the elution profiles in Fig. 4. Thus, while the CD studies indicated that the structure of $\mathrm{CP}-1 \mathrm{O}^{42-55}$ is relatively stable up to $40^{\circ} \mathrm{C}$ in solution, the structural interconversion that occurs at $25^{\circ} \mathrm{C}$ upon interaction with the hydrophobic $\mathrm{C}_{18}$ surface occurs relatively quickly. These differences in apparent relative stability 
between CD and RP-HPLC may relate to the fact that CD measures peptide conformation in a static state while RPHPLC measures the dynamics of conformational transitions and thus provide complementary information on surfaceinduced peptide conformation.

\section{Conclusions}

The CD results presented here indicate that CP- $10^{42-55}$ adopted significant secondary structure in the presence of various hydrophobic solution environments, which is relatively unaffected by temperature. RP-HPLC provided a means of investigating the effect of temperature on the conformation of the peptide in the presence of a hydrophobic surface (i.e. $\mathrm{C}_{18}$-ligands). The retention behaviour of CP$10^{42-55}$ indicated that this peptide exhibited a rapid conformational transition at $25^{\circ} \mathrm{C}$, which was associated with an increase in the chromatographic contact area and the binding affinity of the peptide for the stationary phase.

$\mathrm{CP}-1 \mathrm{O}$ is a calcium-binding protein and a member of the S10o superfamily and it has been proposed that the binding of $\mathrm{Ca}^{2+}$ induces conformational changes in the protein resulting in the exposure of the hydrophobic resdues. Since the peptide $\mathrm{CP}-1 \mathrm{O}^{42-55}$ has been shown to exhibit chemotactic properties similar to the parent CP-10 protein (2), it is possible that calcium binding induces the exposure of the sequence region corresponding to residues $42-55$. While more detailed spectroscopic analysis is required to characterize the conformation of this peptide in different hydrophobic environments, the overall conclusion that can be drawn from these studies is that the strong chemotactic properties of this peptide may be attributed to its ability to form considerable secondary structure in the presence of a hydrophobic surface. In particular, the combination of CD and RP-HPLC has provided insight into the conformational properties of the region encompassing residues $42-55$ of $\mathrm{CP}-10$ in the presence of lipid-like environments that mimic the hydrophobic nature of the cell surface, and provide the basis for future studies on the interaction of this peptide with model lipid systems.

Acknowledgments: The support of the Monash Special Research Fund is gratefully acknowledged. The authors also thank J. Hill for the synthesis of additional quantities of CP-10 $10^{42-55}$.

\section{References}

1. Lackmann, M., Cornish, C.J., Simpson, R.J., Moritz, R.L. \& Geczy, C.L. (1992) Purification and structural analysis of murine chemotactic cytokine (CP-10) with sequence homology to 100 proteins. J. Biol. Chem. 267, 7499-7504.

2. Lackmann, M., Rajasekariah, P., Iismaa, S.E., Jones, G., Cornish, C.J., Hu, S., Simpson, R.J., Moritz, R.L. \& Geczy, C.L. (1993) Identification of a chemotactic domain of the pro-inflammatory $\mathrm{S}_{100}$ protein $\mathrm{CP}-10$ I. Immunol. 150, 2981-2991.

3. Devery, J.M., King, N.J.C. \& Geczy, C.L. (1994) Acute inflammatory activity of the S100 protein CP-10. Activation of neutrophils in vivo and in vitro. J. Immunol. 152, 1888-1897.

4. Kligman, D. \& Hilt, D.C. (1988) The $S_{100}$ protein family. Trends Biol. Sci. 13, 437-443.

5. Lau, W., Devery, J.M. \& Geczy, C.L. (1995) A chemotactic S100 peptide enhances scavenger receptor and Mac-1 expression and cholesteryl ester accumulation in murine peritoneal macrophage in vivo. J. Clin. Invest. 95, 1957-1965.

6. Atherton, E. \& Sheppard, R.C. (1989) Solid Phase Synthesis: A Practical Approach. IRL Press, Oxford.
7. Chen, Y.-H., Yang, J.T. \& Chau, K.H. (1974) Determination of the helix and $\beta$-form of proteins in aqueous solutions by circular dichroism. Biochemistry 13, 3350-3359.

8. Steer, D., Thompson, P.E., Blondelle, S.E., Houghten, R.A. \& Aguilar, M.-I. (1998) Comparison of the binding of $\alpha$-helical and $\beta$-sheet peptides to a hydrophobic surface. J. Peptide Res. 51, 401-412.

9. Padmanabhan, S., Marqusee, S., Ridgeway, T. Laue, T.M. \& Baldwin, R.L. (1990) Relative helix-forming properties of non-polar amino acids. Nature 344, 268-270.

10. Horváth, C.S., Melander, W. \& Molnár, J. (1976) Solvophobic interactions in liquid chromatography with non-polar stationary phase. I. Chromatogr. 125, 129-156.

11. Regnier, F.E. $(1983)$ The role of protein structure in chromatographic behaviour. Science. 238, 319-323.

12. Lazoura, E., Maidonis, I., Bayer, E., Hearn, M.T.W. \& Aguilar, M.-I. (1997) Conformational analysis of neuropeptide Y-[18-36] analogues in hydrophobic environments. Biophys. J. 72, 1-9.
13. Lee, T.-Z., Thompson, P.E., Hearn, M.T.W. \& Aguilar, M.I. (1997) Conformational stability of a type $\mathrm{II}^{\prime} \beta$-turn motif in human growth hormone [6-13] peptide analogues at hydrophobic surfaces. J. Peptide Res. 49, 394-403.

14. Hodges, R.S., Zhu, B.-Y., Zhou, N.E. \& Mant, C.T. (1994) Reversed-phase liquid chromatography as a probe of hydrophobic interactions involved in protein folding and protein stability. J. Chromatogr. A 676, 3-15.

15. Blondelle, S.E. \& Houghten, R.A. (1991) Hemolytic antimicrobial activities of the twenty-four individual analogues of melittin. Biochemistry 30, 4671-4678.

16. Blondelle, S.E., Simpkins, L.R., Perez-Payá, E. \& Houghten, R.A. (1993) Influence of tryptophan residues on melittin's hemolytic activity. Biochim. Biophys. Acta 1202, 331-336.

17. Snyder, L.R. (1980) Gradient elution. In HPLC: Advances and Perspectives (Horváth, CS., ed.). Academic Press, New York, pp. 207-316. 
18. Stadalius, M.A., Gold, H.S. \& Snyder, L.R. (1984) Optimization model for the gradient elution separation of peptide mixtures by reversed-phase high performance liquid chromatography. J. Chromatogr. 296, 31-59.

19. Purcell, A.W., Aguilar, M.-I. \& Hearn, M.T.W. (1989) Investigations into the relationship between structure, RP-HPLC retention behaviour and biological activity of peptides relate to human growth hormone. J. Chromatogr. 476, 113-125.
20. Aguilar, M.-I., Richards, K.L., Round, A.J. \& Hearn, M.T.W. (1994) Molecular definition of the retention parameters of peptides separated by RP-HPLC. Peptide Res. 7, 207-217.

21. Richards, K.L., Aguilar, M.-I. \& Hearn, M.T.W. (1994) A comparative study of the retention behaviour and stability of cytochrome $c$ in reversed-phase highperformance liquid chromatography.

J. Chromatogr. A 676, 17-31.
22. Purcell, A.W., Aguilar, M.-I. \& Hearn, M.T.W. (1993) Dynamics of peptides in reversed-phase liquid chromagraphy. Anal. Chem. 65, 3038-3047. 